\title{
Terahertz Spectra of L-phenylalanine and Its Monohydrate
}

Tingting Pan ${ }^{1,2}$, Shaoping $\mathrm{Li}^{1 *}$, Tao Zou ${ }^{1,2}$, Zheng $\mathrm{Yu}^{2}$, Bo Zhang ${ }^{1,2}$, Chenyang Wang ${ }^{2}$,

Jianbing Zhang ${ }^{2}$, Mingxia $\mathrm{He}^{3}$, Hongwei Zhao ${ }^{2 *}$

${ }^{I}$ School of Chemical Engineering, East China University of Science and Technology, Shanghai 200237, China

${ }^{2}$ Division of Interfacial Water and Key Laboratory of Interfacial Physics and Technology, Shanghai Institute of Applied Physics, Chinese Academy of Sciences, Shanghai 201800, China

${ }^{3}$ State Key Laboratory of Precision Measuring Technology and Instruments, School of Precision Instrument and Opto-electronics Engineering, Tianjin University, Tianjin 300072, China

*Corresponding author. E-mail addresses: zhaohongwei@ sinap.ac.cn and spli@ecust.edu.cn.

\begin{abstract}
The low-frequency vibrational property of L-phenylalanine (L-Phe) and L-phenylalanine monohydrate $\left(\mathrm{L}-\mathrm{Phe} \cdot \mathrm{H}_{2} \mathrm{O}\right)$ has been investigated by terahertz time-domain spectroscopy (THz-TDS) at room and low temperature ranging from 0.5 to $4.5 \mathrm{THz}$. Distinctive $\mathrm{THz}$ absorption spectra of the two compounds were observed. Density functional theory (DFT) calculations based on the crystal structures have been performed to simulate the vibrational modes of L-Phe and L-Phe $\cdot \mathrm{H}_{2} \mathrm{O}$ and the results agree well with the experimental observations. The study indicates that the characterized features of L-Phe mainly originate from the collective vibration of molecules. And the characterized features of L-Phe $\cdot \mathrm{H}_{2} \mathrm{O}$ mainly come from hydrogen bond interactions between L-Phe and water molecules. L-Phe and L-Phe $\cdot \mathrm{H}_{2} \mathrm{O}$ were also verified by differential scanning calorimetry and thermogravimetry (DSC-TG) and powder X-ray diffraction (PXRD) examinations.
\end{abstract}

Key words: L-phenylalanine, monohydrate, terahertz absorption spectrum, low-frequency vibration, DFT 


\section{Introduction}

L-phenylalanine (L-Phe) is important as an essential amino acid for human nutrition and is widely used as food or feed additive, in infusion fluids, and for chemical syntheses of pharmaceutically active compounds[1-3]. L-Phe has been found to have two solid forms, anhydrous form and monohydrate form which is known as polymorphism[4, 5]. Different pseudopolymorphs can have vastly different product characteristics such as bioavailability, solubility, mechanical behavior, stability, dissolution rate and shelf-life[6-8]. Incorporation of water of crystallization of L-Phe changes the molecular structure and also changes its active pharmaceutical ingredients (API) performance characteristics[9-11]. Water molecule has the capability to act both as hydrogen bond donor and acceptor and can therefore affect the intermolecular interactions and packing in L-Phe molecules[10]. And the forces holding these crystals together originate from hydrogen bonding, van der Waals interactions, and electrostatic interactions[12]. Therefore, it is critically important to understand and monitor the anhydrate and its hydrate forms of L-Phe.

Terahertz (THz) spectroscopy is an alternative and novel technique for study the structure and interactions of chemical materials[13, 14]. It is highly sensitive to the hydrogen bonding, lattice vibration and water of crystallization[10, 15]. Recently, Zeitler et al.[16] successfully distinguished the different hydrate and anhydrate forms of four pharmaceutical materials including lactose, carbamazepine, piroxicam and theophylline by the use of $\mathrm{THz}$ pulsed spectroscopy. Zheng et al.[17] investigated the THz spectra of anhydrous and monohydrated glucose by using THz spectroscopy and DFT theoretical calculation. They found the characterized features of monohydrated glucose mainly come from the intermolecular modes of water-glucose and glucose-glucose molecules, while those of anhydrous glucose origin from the interactions of glucose molecules. Liu et al.[18] found the $\mathrm{THz}$ spectra of pharmaceutical substances including caffeine, theophylline, D-glucose, and ampicillin exhibit different features from their hydrated forms, presumably due to their different intermolecular vibrational modes mediated by hydrogen-bonding. As for L-Phe, 
Miyamaru et al.[19] observed one broad peak at 2.72 THz. Wang et al.[20] reported $\mathrm{THz}$ spectra of 20 alpha-amino acids including Phe. Li et al.[21] investigated the experimental $\mathrm{THz}$ spectrum of Phe in the frequency ranging from 0.2 to $2.8 \mathrm{THz}$ and also simulated the vibrational modes based on the isolated molecule, nevertheless, what kind of samples' chirality were not mentioned. These works provide useful information of molecular recognition and intermolecular interaction in low-frequency. However, the characterization of L-Phe monohydrate $\left(\mathrm{L}-\mathrm{Phe} \cdot \mathrm{H}_{2} \mathrm{O}\right)$ form in $\mathrm{THz}$ region has not been reported and the analysis of vibrational modes of anhydrous and hydrous L-Phe is still insufficient. In this paper, we investigated the $\mathrm{THz}$ spectra of L-Phe and L-Phe $\cdot \mathrm{H}_{2} \mathrm{O}$ ranging from 0.5 to $4.5 \mathrm{THz}$. And the temperature effect was investigated. The hydrous and anhydrous forms of the samples were also verified by differential scanning calorimetry and thermogravimetry (DSC-TG) and powder X-ray diffraction (PXRD) examinations.

Quantum chemical calculations were performed to simulate the vibrational properties of L-Phe and L-Phe $\cdot \mathrm{H}_{2} \mathrm{O}$ molecules to help understanding the $\mathrm{THz}$ experimental observation and the molecular interactions. The simulations were carried out based on the crystal structure and multiple molecules are involved. DFT calculations were applied using the CASTEP program as a part of Materials Studio package from Accelrys and the results agree well with the experimental observations.

\section{Materials and Methods}

\subsection{Materials}

The sample of L-Phe was purchased from J\&K Co. Ltd. (purity > 98\%). Polyethylene powder (PE) (particle size 53-75 $\mu \mathrm{m}$ ) was purchased from Sigma-Aldrich Co. LLC. The samples were used without further purification.

L-Phe $\cdot \mathrm{H}_{2} \mathrm{O}$ was obtained by recrystallization from water[22]. DSC-TG and PXRD were used for characterization the hydrate yielded.

\subsection{Sample preparation}

The powder of samples for THz detection were blended with PE powder at a mass 
ratio of 1:5 and then pressed into disks with a hydraulic press at a pressure of $3.0 \mathrm{MPa}$. The thicknesses of the sample tablets were approximately $1.2-1.3 \mathrm{~mm}$, and the diameter was $13 \mathrm{~mm}$.

\subsection{THz time-domain spectroscopy (THz-TDS)}

THz spectra of L-Phe and L-Phe $\cdot \mathrm{H}_{2} \mathrm{O}$ were measured using a TAS7400TS THz-TDS system (Advantest Corporation, Japan) ranging from 0.5 to $4.5 \mathrm{THz}$. The frequency resolution is $1.9 \mathrm{GHz}$. The number of scans is 1024 . The sample was placed into the THz system which was purged with drying air. The data was an average of three. PE was used as reference. The software used for the data evaluation was Origin.

\subsection{Temperature controller}

The pellets were placed into temperature controller (Specac Ltd. U.K., the accuracy $\pm 0.5^{\circ} \mathrm{C}$ ) which is equipped with high-density polyethylene windows. The liquid nitrogen was put into the variable temperature cavity. THz spectra of L-Phe and $\mathrm{L}-\mathrm{Phe} \cdot \mathrm{H}_{2} \mathrm{O}$ were recorded over the temperature range from -180 to $-40{ }^{\circ} \mathrm{C}$.

\subsection{Differential scanning calorimetry and thermogravimetry (DSC-TG)}

DSC-TG was performed using on STA 449 F3 Jupiter (NETZSCH). Sample was put in a corundum crucible with a lip on it (L-Phe: $6.104 \mathrm{mg}, \mathrm{L}-\mathrm{Phe} \cdot \mathrm{H}_{2} \mathrm{O}: 6.512 \mathrm{mg}$ ), and heated ranging from 35 to $300{ }^{\circ} \mathrm{C}$ with a heating rate of $10{ }^{\circ} \mathrm{C} / \mathrm{min}$ under $\mathrm{Ar}$ atmosphere $(60 \mathrm{~mL} / \mathrm{min})$. The software used for the data evaluation was Origin.

\subsection{Powder X-ray diffraction (PXRD)}

PXRD patterns of L-Phe and L-Phe $\cdot \mathrm{H}_{2} \mathrm{O}$ were recorded using the X'Pert Pro MPD ( $\mathrm{Cu}$ source, $40 \mathrm{kV}$ voltage, $40 \mathrm{~mA}$ filament emission). The data were collected with a scan ranging from $10^{\circ}$ to $90^{\circ}(2 \theta)$. The scan rate was $0.2^{\circ} / \mathrm{min}$. The software used for the data evaluation was Xpert Highscore.

\section{Quantum Chemical Calculation}

The total energy optimization and the frequency calculations were performed based on the DFT using the CASTEP[23] program as a part of Materials Studio package from Accelrys. The simulation of L-Phe and L-Phe $\cdot \mathrm{H}_{2} \mathrm{O}$ were performed using the crystal 
cell parameters taken from King et al. Ref[24] and Williams et al. Ref[25] respectively and the calculations of $\mathrm{THz}$ spectra were performed on the strength of the geometry optimized structure. The space group of L-Phe crystal is $P 2(\mathrm{Z}=8)$, with lattice dimensions of $a=8.7407 \AA, b=6.0412 \AA, c=31.3941 \AA, \alpha=90^{\circ}, \beta=97.745^{\circ}, \gamma=90^{\circ}$. And the space group of $\mathrm{L}-\mathrm{Phe} \cdot \mathrm{H}_{2} \mathrm{O}$ crystal is $P 2_{1}(\mathrm{Z}=4)$, with lattice dimensions of $a=13.05$ $\AA, b=5.44 \AA, c=13.98 \AA, \alpha=90^{\circ}, \beta=101.2^{\circ}, \gamma=90^{\circ}$. The calculations were performed on the crystalline state within the generalized gradient approximation (GGA) at PBE (Perdew-Burke-Ernzerhof correlation) functional[26]. Calculations were performed using norm-conserving pseudopotential. The quality of energy calculations were ultra-fine. The plane-wave cut-off energy was $830 \mathrm{eV}$. For L-Phe and L-Phe- $\mathrm{H}_{2} \mathrm{O}$, Brillouin zone sampling of electronic states were performed on $2 \times 2 \times 1$ and $1 \times 3 \times 1$ Monkhorst-Pack grid respectively, and the total energy was converged to $5.0 \times 10^{-6}$ $\mathrm{eV} /$ atom and the maximum forces between atoms were less than $0.01 \mathrm{eV} / \mathrm{A}$. The grids for fast Fourier transform were $90 \times 60 \times 300$ and $125 \times 54 \times 135$ respectively.

\section{Result and Discussion}

\section{1 $\mathrm{THz}$ analysis and temperature effect}

The THz absorption spectra of L-Phe and L-Phe $\cdot \mathrm{H}_{2} \mathrm{O}$ at both $25{ }^{\circ} \mathrm{C}$ and $-180{ }^{\circ} \mathrm{C}$ respectively are shown in Figure 1. At room temperature, L-Phe shows two strong peaks at 2.81 and $4.19 \mathrm{THz}$, two less pronounced bands at 1.17, 1.99 respectively. The L-Phe $\cdot \mathrm{H}_{2} \mathrm{O}$ has two strong peaks at $3.09,4.03 \mathrm{THz}$, two obvious peaks at $0.93,1.48$ $\mathrm{THz}$, and relative weaker peaks at 1.71, $1.92 \mathrm{THz}$. The absorption peak of L-Phe located at $1.99 \mathrm{THz}$ is consistent with Wang and $\mathrm{Li}[20,21]$. Since the chiral amino acid molecules always present different crystalline structures between the enantiomers and the racemate[27], and the different crystal packing arrangements always show different responses to THz radiation[28]. Therefore, we infer that the sample of the Phe they used probably is not the racemate. Though both of L-Phe and L-Phe $\cdot \mathrm{H}_{2} \mathrm{O}$ present relative weak absorption peaks before $2 \mathrm{THz}$, their whole features are obviously different. 
The absorption peaks usually become stronger and sharper at low temperature, owing to the temperature dependent change in the distribution of occupied energy states[29]. For L-Phe, a new peak arises at $2.30 \mathrm{THz}$. And the broad peak at $2.81 \mathrm{THz}$ at room temperature split into three peaks at $2.85,3.22,3.41 \mathrm{THz}$ at $-180^{\circ} \mathrm{C}$. As shown in Figure 1, the absorption peaks blue-shifted with the temperature decreasing. Such a shift is usually attributed to the increased bond lengths due to thermal expansion with warming. And the degree of blue shift is different at each absorption peak, probably because different vibrational modes have different response degree to the temperature change[30]. The result indicates that $\mathrm{THz}$ spectra are sensitive to temperature. And the evolution of the $\mathrm{THz}$ spectra in the temperature ranging from $-180{ }^{\circ} \mathrm{C}$ to $-40{ }^{\circ} \mathrm{C}$ was measured (supplementary information).

The result indicates that $\mathrm{THz}$ spectroscopy is sensitive to the different forms of L-Phe, and the characteristic $\mathrm{THz}$ fingerprints can be used in detection and identification applications. Considering the different physical forms and the crystalline structures of a sample always show different responses to $\mathrm{THz}$ radiation, PXRD was carried out to characterize the samples in this study.

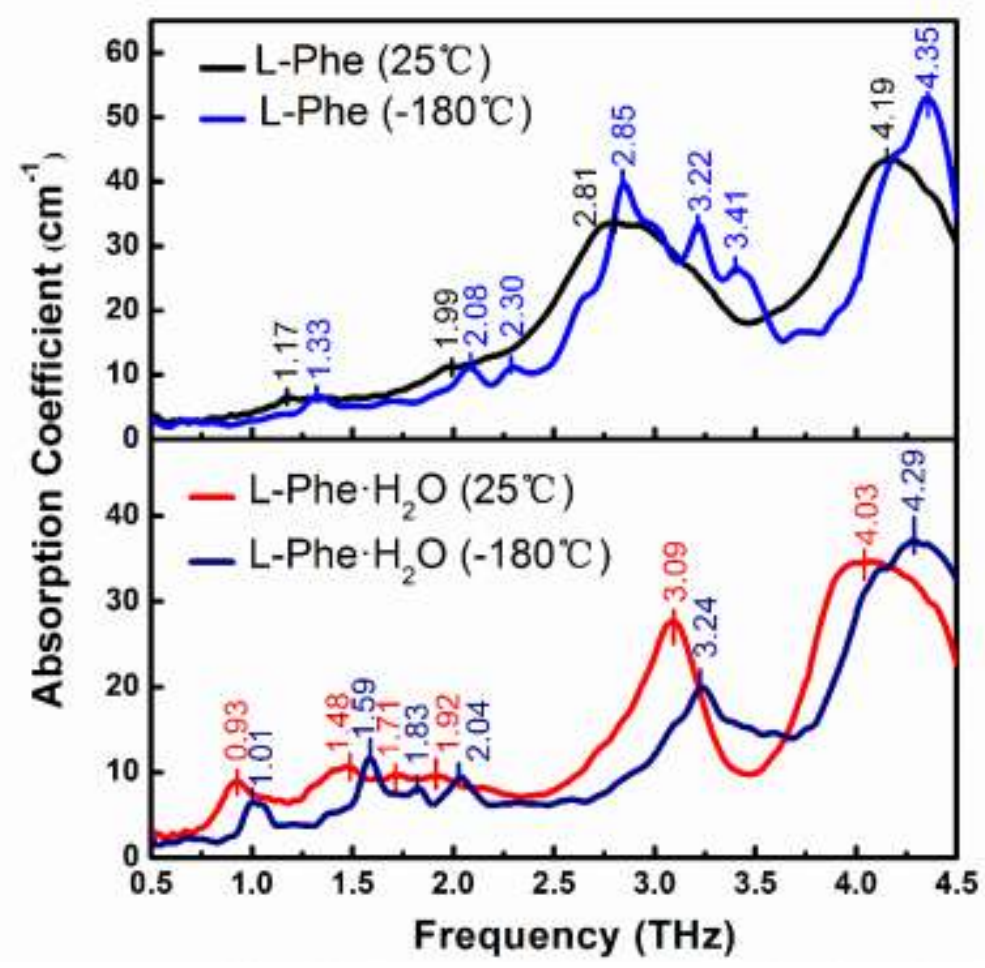


Figure 1. THz absorption spectra of L-Phe and L-Phe $\cdot \mathrm{H}_{2} \mathrm{O}$.

\subsection{DSC-TG analysis}

Figure 2 shows the results of L-Phe and L-Phe $\cdot \mathrm{H}_{2} \mathrm{O}$ obtained by DSC-TG thermal analysis. The L-Phe shows three endothermic peaks at 263.7, 278.7 and $293.9{ }^{\circ} \mathrm{C}$, corresponding to the simultaneous processes of melting and decomposition of the sample. And it can be confirmed from TG curve which is accompanied by a significant weight loss. As to L-Phe $\cdot \mathrm{H}_{2} \mathrm{O}$, another endothermic peak occurs at $88.7{ }^{\circ} \mathrm{C}$ and corresponds to dehydration and has the accompanying weight change. The result is agree with previous report by $\mathrm{Lu}$ et al.[31].

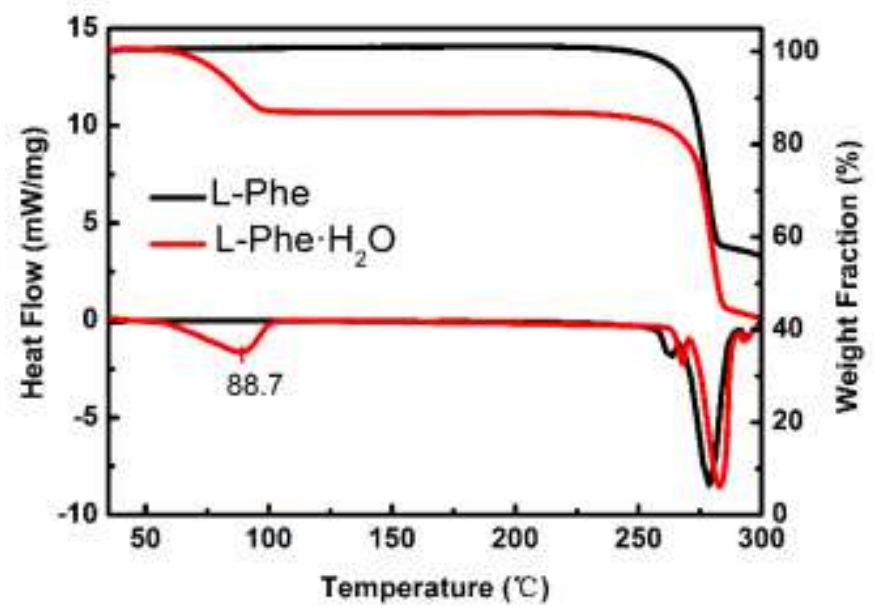

Figure 2. The DSC-TG curves of L-Phe and L-Phe $\cdot \mathrm{H}_{2} \mathrm{O}$.

\subsection{PXRD patterns of $\mathrm{L}$-Phe and $\mathrm{L}-\mathrm{Phe} \cdot \mathrm{H}_{2} \mathrm{O}$}

The crystal structure of L-Phe and L-Phe $\cdot \mathrm{H}_{2} \mathrm{O}$ were confirmed by PXRD measurements. The patterns are shown in Figure 3, and both of L-Phe and L-Phe $\cdot \mathrm{H}_{2} \mathrm{O}$ present specific diffraction patterns which are consistent with the previous published crystal database[24, 25]. Therefore, the DFT simulations were performed based on their crystal cell parameters. The significant differences of their crystal structures suggest the presence of water directly influence the spatial arrangement of L-Phe molecules. In $\mathrm{L}-\mathrm{Phe} \cdot \mathrm{H}_{2} \mathrm{O}$, each water molecule is engaged in hydrogen bonding to L-Phe molecule and the hydrogen bonding network can lead to the change of the crystal lattice. 


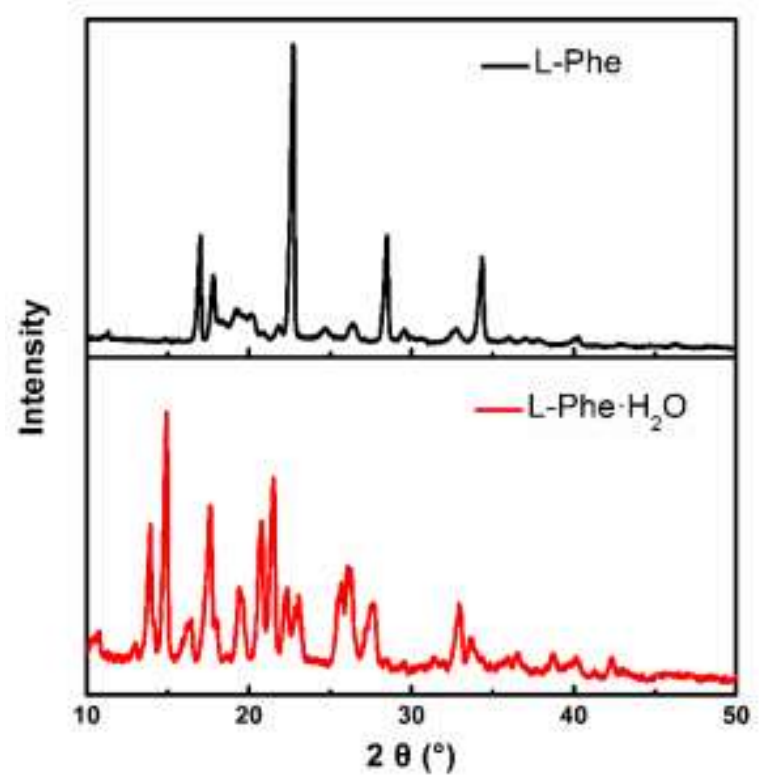

Figure 3. Powder X-ray diffraction patterns for L-Phe and L-Phe $\cdot \mathrm{H}_{2} \mathrm{O}$.

\subsection{Quantum chemical calculation}

The interpretation and understanding of the experimental $\mathrm{THz}$ spectra are still a fundamental scientific challenge at present. Some theoretical simulations and calculations have been suggested as effective means to bridge the observed low-frequency vibrational modes and the molecular structures and interactions[14, 32-34]. And the simulations based on crystal cells which involve the intermolecular interactions have been suggested more reliable compared to isolated molecule[35].

The simulated THz spectra produced by solid-state DFT calculations are plotted against the experimental $\mathrm{THz}$ spectra of L-Phe and $\mathrm{L}-\mathrm{Phe} \cdot \mathrm{H}_{2} \mathrm{O}$ in Figure 4(a) and 5(a), the vibrational modes of L-Phe and L-Phe $\cdot \mathrm{H}_{2} \mathrm{O}$ were demonstrated in Figure 4(b) and Figure 5(b), respectively. The descriptions of the calculated vibrational modes of L-Phe and L-Phe $\cdot \mathrm{H}_{2} \mathrm{O}$ were presented in Table 1 .

For L-Phe, The experimental spectral feature at $1.99 \mathrm{THz}$ corresponds to the vibrational mode calculated at $1.91 \mathrm{THz}$, arising from translation of L-Phe. This peak was suggested as wagging of $-\mathrm{NH}_{2}$ and ring structure out-of-plane in previous study based on an isolated molecule simulation[21]. The broad peak at $2.81 \mathrm{THz}$ at $25{ }^{\circ} \mathrm{C}$ which is split into three peaks at $-180{ }^{\circ} \mathrm{C}$ can be attributed to the calculated mode from 2.78 to $3.39 \mathrm{THz}$, arising from rotation and translation of L-Phe. 

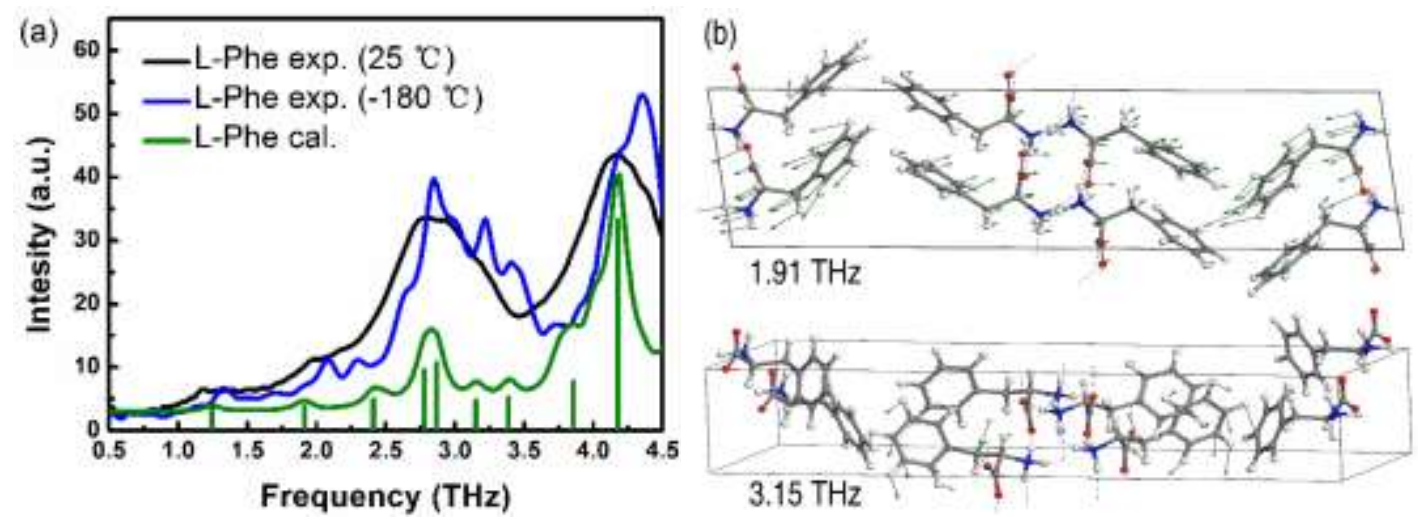

Figure 4. The experimental and calculated spectra of L-Phe. (a) THz spectra of L-Phe from simulated and the corresponding experiment. (b) The vibrational modes of L-Phe at $1.91 \mathrm{THz}$ and $3.15 \mathrm{THz}$.

For L-Phe $\mathrm{H}_{2} \mathrm{O}$, the measured feature at $0.93 \mathrm{THz}$ is produced by the calculated mode at $0.97 \mathrm{THz}$, which originates from rotation and translation of L-Phe mixed with translation of water molecules. The observed peak at $3.09 \mathrm{THz}$ is attributed to intermolecular hydrogen bond vibration besides torsion of L-Phe and translation of water molecules. And the strong absorption centered at $4.03 \mathrm{THz}$ is much similar with that of $3.09 \mathrm{THz}$.
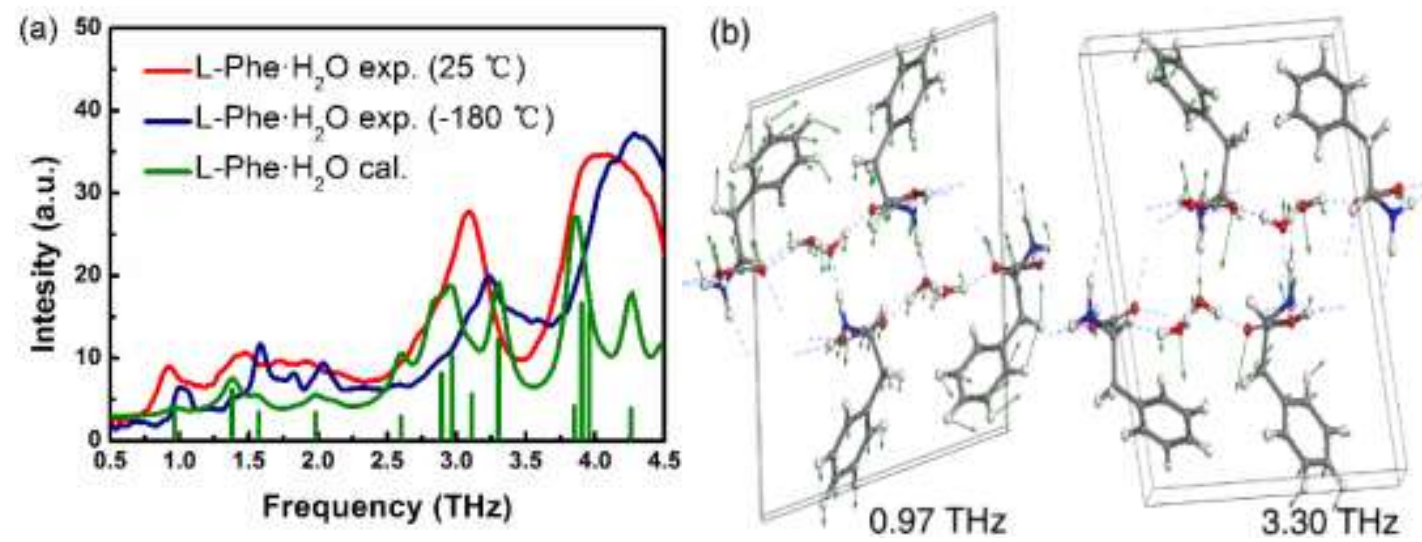

Figure 5. The experimental and calculated spectra of L-Phe $\cdot \mathrm{H}_{2} \mathrm{O}$. (a) THz spectra of L-Phe $\cdot \mathrm{H}_{2} \mathrm{O}$ from simulated and the corresponding experiment. (b) The vibrational modes of $\mathrm{L}-\mathrm{Phe} \cdot \mathrm{H}_{2} \mathrm{O}$ at $0.97 \mathrm{THz}$ and $3.30 \mathrm{THz}$.

The molecular vibration of L-Phe in $\mathrm{THz}$ region involves most of atoms even collective vibration of all molecules. The hydrogen bonding network involves intermolecular $\mathrm{N}-\mathrm{H} \cdots \mathrm{O}$ hydrogen bonds between the carboxylate and amine groups.

Incorporation of the water molecules in the crystal lattice of L-Phe changes the dimensions, shape, symmetry and number of molecules of the unit cell. And additional bonds formation between the L-Phe molecules and the water molecules lead to the 
change of intermolecular interactions. The change of unit cell leads to the significant difference of $\mathrm{THz}$ spectra.

In the L-Phe $\cdot \mathrm{H}_{2} \mathrm{O}$ structure, the two crystallographically distinct water molecules are engaged in $\mathrm{O}-\mathrm{H} \cdots \mathrm{O}$ hydrogen bonding with each other. And one water molecule forms $\mathrm{O}-\mathrm{H} \cdots \mathrm{O}$ hydrogen bond with L-Phe molecule. The other water molecule forms $\mathrm{O}-\mathrm{H} \cdots \mathrm{O}$ hydrogen bond with carboxylate group of L-Phe molecule and $\mathrm{N}-\mathrm{H} \cdots \mathrm{O}$ hydrogen bond with ammonium group of a different L-Phe molecule. These hydrogen bonds strengthen governing lattice vibration as an important component to maintain the stability of lattice pattern.

Table 1. The descriptions of calculated vibrational modes and corresponding experimental peaks of L-Phe and L-Phe $\cdot \mathrm{H}_{2} \mathrm{O}^{\alpha}$

\begin{tabular}{|c|c|c|c|c|}
\hline \multirow[t]{2}{*}{ Compound } & \multicolumn{2}{|c|}{$\begin{array}{l}\text { Experimental } \\
\text { peak }(\mathrm{THz})\end{array}$} & \multirow{2}{*}{$\begin{array}{l}\text { Calculated } \\
\text { mode }(\mathrm{THz})\end{array}$} & \multirow[t]{2}{*}{ Mode description } \\
\hline & $25^{\circ} \mathrm{C}$ & $-180^{\circ} \mathrm{C}$ & & \\
\hline \multirow{9}{*}{ L-Phe } & 1.17 & 1.33 & 1.24 & Rotation \\
\hline & 1.99 & 2.08 & 1.91 & Translation \\
\hline & \multirow{5}{*}{2.81} & 2.30 & 2.41 & Rotation \\
\hline & & \multirow{2}{*}{2.85} & 2.78 & Rotation and translation \\
\hline & & & 2.87 & Rotation \\
\hline & & 3.22 & 3.15 & Rotation of $-\mathrm{Ph}$ \\
\hline & & 3.41 & 3.39 & Rotation of $-\mathrm{Ph}$ \\
\hline & \multirow{2}{*}{4.19} & \multirow{2}{*}{4.35} & 3.86 & Rotation of $-\mathrm{Ph}$ \\
\hline & & & 4.18 & Rotation of $-\mathrm{Ph}$ \\
\hline \multirow{8}{*}{$\mathrm{L}-\mathrm{Phe} \cdot \mathrm{H}_{2} \mathrm{O}$} & 0.93 & 1.01 & 0.97 & $\begin{array}{l}\text { Rotation and translation of L-Phe and } \\
\text { translation of } \mathrm{H}_{2} \mathrm{O}\end{array}$ \\
\hline & 1.48 & 1.59 & 1.38 & Rotation of L-Phe and translation of $\mathrm{H}_{2} \mathrm{O}$ \\
\hline & 1.71 & 1.83 & 1.57 & $\begin{array}{l}\text { Rotation and translation of L-Phe and } \\
\text { translation of } \mathrm{H}_{2} \mathrm{O}\end{array}$ \\
\hline & 1.92 & 2.04 & 1.98 & Rotation of L-Phe \\
\hline & \multirow{4}{*}{3.09} & \multirow{4}{*}{3.24} & 2.60 & Wagging of $-\mathrm{Ph}$ and translation of $\mathrm{H}_{2} \mathrm{O}$ \\
\hline & & & 2.89 & Wagging of - $\mathrm{Ph}$ and translation of $\mathrm{H}_{2} \mathrm{O}$ \\
\hline & & & 2.97 & Torsion of L-Phe and translation of $\mathrm{H}_{2} \mathrm{O}$ \\
\hline & & & 3.11 & Wagging of $-\mathrm{Ph}$ \\
\hline
\end{tabular}


3.30

4.03
Torsion of L-Phe and translation of $\mathrm{H}_{2} \mathrm{O}$ and $\mathrm{HB}$ vibration

Torsion of L-Phe and translation of $\mathrm{H}_{2} \mathrm{O}$ and $\mathrm{HB}$ vibration

Wagging of $-\mathrm{Ph}$

Torsion of L-Phe and translation of $\mathrm{H}_{2} \mathrm{O}$ and $\mathrm{HB}$ vibration

Torsion of L-Phe and translation of $\mathrm{H}_{2} \mathrm{O}$ and $\mathrm{HB}$ vibration

a "HB" stands for hydrogen bond; "-Ph" for -phenyl.

Although the quantum chemical calculation provides us with much valuable information, there are some offset compared with the experimental results. And the following reasons may be worth considering, such as the temperature effect of experiments and simulations, humidity of environment, system error of experimental measurements etc. In addition, the disparity of crystals situations in actual experiments and theoretical simulations also need to take into consideration, since the calculation is based on the perfect crystal structure, while the actual system is difficult to idealize.

\section{Conclusions}

In this work, L-Phe and L-Phe $\cdot \mathrm{H}_{2} \mathrm{O}$ were investigated by THz-TDS at room and low temperature. Different crystalline structures of them are found to be the main reason for the different $\mathrm{THz}$ spectral features. The result indicates that $\mathrm{THz}$ wave is sensitive to differences of crystal structure. And the absorption peaks become stronger and narrower at low temperature. DSC-TG and PXRD were performed to investigate the thermodynamic properties and molecular packing patterns of L-Phe and L-Phe $\cdot \mathrm{H}_{2} \mathrm{O}$. The THz spectra were simulated by solid-state DFT, producing high-quality spectral simulations for L-Phe and L-Phe $\cdot \mathrm{H}_{2} \mathrm{O}$. The study indicates that the characterized features of L-Phe mainly originate from the collective vibration of the molecules. And the characterized features of L-Phe $\cdot \mathrm{H}_{2} \mathrm{O}$ mainly come from hydrogen bond interactions between L-Phe and water molecules. This study demonstrates the feasibility of utilizing THz spectroscopy for pharmaceutical applications. 
Additional Supporting Information may be found in the online version of this article.

\section{Acknowledgments}

This work was supported by the Main Direction Program of Knowledge Innovation; Open Project Program of Key Laboratory of Interfacial Physics and Technology, Chinese Academy of Sciences, China; and the National Science Foundation [No. 10574134, 61675151], National Basic Research Program of China [No. 2014CB339806]. 


\section{Reference}

[1] S.R. Jia, J.D. Cui, Y. Li, A.Y. Sun, Production of L-phenylalanine from trans-cinnamic acids by high-level expression of phenylalanine ammonia lyase gene from Rhodosporidium toruloides in Escherichia coli, Biochem Eng J, 42 (2008) 193-197. http://dx.doi.org/10.1016/j.bej.2008.06.010

[2] X. Sun, X.J. Liu, X.J. Xu, P. Sun, Molecular structure, spectroscopic, chemical reactivity, and nonlinear optical analysis of L-phenylalanine-benzoic acid optical crystals, Optik, 127 (2016) 4881-4888. http://dx.doi.org/10.1016/j.ijleo.2016.02.015

[3] M.B. Mary, V. Sasirekha, V. Ramakrishnan, Laser Raman and infrared spectral studies of DL-phenylalaninium nitrate, Spectrochim Acta A, $62 \quad$ (2005) 446-452. http://dx.doi.org/10.1016/j.saa.2005.01.013

[4] R.K. Harris, NMR studies of organic polymorphs \& solvates, Analyst, 131 (2006) 351-373. http://dx.doi.org/10.1039/b516057j

[5] G.R. Ramkumaar, S. Srinivasan, T.J. Bhoopathy, S. Gunasekaran, Quantum chemical and experimental studies on polymorphism of antiviral drug Lamivudine, Spectrochim Acta A, 98 (2012) 265-270. http://dx.doi.org/10.1016/j.saa.2012.08.013

[6] N. Chieng, T. Rades, J. Aaltonen, An overview of recent studies on the analysis of pharmaceutical $\begin{array}{llllll}\text { polymorphs, } & \mathrm{J} & \text { Pharmaceut } & \text { Biomed, } & 55 & \text { (2011) }\end{array}$ http://dx.doi.org/10.1016/j.jpba.2010.12.020

[7] B. Bechtloff, S. Nordhoff, J. Ulrich, Pseudopolymorphs in industrial use, Cryst Res Technol, 36 (2001) 1315-1328. http://dx.doi.org/10.1002/1521-4079(200112)36:12<1315::AID-CRAT1315>3.0.CO;2-R

[8] Y. Du, Y. Xia, H.L. Zhang, Z. Hong, Using terahertz time-domain spectroscopical technique to 
monitor cocrystal formation between piracetam and 2,5-dihydroxybenzoic acid, Spectrochim Acta A, 111 (2013) 192-195. http://dx.doi.org/10.1016/j.saa.2013.03.081

[9] Y. Du, H.L. Zhang, J.D. Xue, W.J. Tang, H.X. Fang, Q. Zhang, Y.F. Li, Z. Hong, Vibrational spectroscopic study of polymorphism and polymorphic transformation of the anti-viral drug $\begin{array}{lllll}\text { lamivudine, } & \text { Spectrochim } & \text { Acta } & \text { A, } & 137\end{array}$ http://dx.doi.org/10.1016/j.saa.2014.08.128

[10] A.C. Jorgensen, C.J. Strachan, K.H. Pollanen, V. Koradia, F. Tian, J. Rantanen, An insight into water of crystallization during processing using vibrational spectroscopy, J Pharm Sci, 98 (2009) 3903-3932. http://dx.doi.org/10.1002/jps.21735

[11] J. Lu, S. Rohani, Polymorphism and crystallization of active pharmaceutical ingredients (APIs), Curr Med Chem, 16 (2009) 884-905. http://dx.doi.org/10.2174/092986709787549299

[12] M. Takahashi, Terahertz vibrations and hydrogen-bonded networks in crystals, Crystals, 4 (2014) 74-103. . http://dx.doi.org/10.3390/cryst4020074

[13] T. Gaillard, A. Trivella, R.H. Stote, P. Hellwig, Far infrared spectra of solid state L-serine, L-threonine, L-cysteine, and L-methionine in different protonation states, Spectrochim Acta A, 150 (2015) 301-307. http://dx.doi.org/10.1016/j.saa.2015.05.031

[14] M.D. King, W.D. Buchanan, T.M. Korter, Understanding the terahertz spectra of crystalline pharmaceuticals: terahertz spectroscopy and solid-state density functional theory study of (S)-(+)-ibuprofen and (RS)-ibuprofen, $\quad \mathrm{J} \quad$ Pharm $\quad$ Sci, $100 \quad$ (2011) 1116-1129. http://dx.doi.org/10.1002/jps.22339

[15] L. Ho, M. Pepper, P. Taday, Terahertz spectroscopy signatures and fingerprints, Nat Photonics, 2 (2008) 541-543. http://dx.doi.org/10.1038/nphoton.2008.174 
[16] J.A. Zeitler, K. Kogermann, J. Rantanen, T. Rades, P.F. Taday, M. Pepper, J. Aaltonen, C.J. Strachan, Drug hydrate systems and dehydration processes studied by terahertz pulsed spectroscopy, Int $\mathbf{J}$ Pharmaceut, 334 (2007) 78-84. http://dx.doi.org/10.1016/j.ijpharm.2006.10.027

[17] Z.P. Zheng, W.H. Fan, H. Li, J. Tang, Terahertz spectral investigation of anhydrous and monohydrated glucose using terahertz spectroscopy and solid-state theory, J Mol Spectrosc, 296 (2014) 9-13. http://dx.doi.org/10.1016/j.jms.2013.12.002

[18] H.B. Liu, Y.Q. Chen, X.C. Zhang, Characterization of anhydrous and hydrated pharmaceutical materials with THz time-domain spectroscopy, J Pharm Sci, 96 (2006) 927-934. http://dx.doi.org/10.1002/jps.20782

[19] F. Miyamaru, M. Yamaguchi, M. Tani, THz-time-domain spectroscopy of amino acids in solid phase, $\begin{array}{lllll}\text { Conference } & \text { on } & \text { Lasers }\end{array}$ https://www.infona.pl/resource/bwmeta1.element.ieee-art-000001297735

[20] W.N. Wang, H.Q. Li, Y. Zhang, C.L. Zhang, Correlations between terahertz spectra and molecular structures of 20 standard alpha-amino acids, Acta Phys-Chim Sin, 25 (2009) 2074-2079. http://dx.doi.org/10.3866/PKU.WHXB20090931

[21] Y.B. Li, Y.Y. Zheng, W.N. Wang, THz spectrum and vibrational mode of phenylalanine, Conference Digest of the 2006 Joint 31st International Conference on Infrared and Millimeter Waves and 14th International Conference on Terahertz Electronics, WedP-11 (2006) 422-422. http://dx.doi.org/10.1109/ICIMW.2006.368630

[22] J. Lu, Q. Lin, Z. Li, S. Rohani, Solubility of L-phenylalanine anhydrous and monohydrate forms: experimental measurements and predictions, J Chem Eng Data, 57 (2012) 1492-1498. http://dx.doi.org/10.1021/je201354k 
[23] S.J. Clark, M.D. Segall, C.J. Pickard, P.J. Hasnip, M.J. Probert, K. Refson, M.C. Payne, First principles methods using CASTEP, Z Kristallogr, $220 \quad$ (2005) 567-570. http://dx.doi.org/10.1524/zkri.220.5.567.65075

[24] M.D. King, T.N. Blanton, T.M. Korter, Revealing the true crystal structure of L-phenylalanine using solid-state density functional theory, Phys Chem Chem Phys, 14 (2012) 1113-1116. http://dx.doi.org/10.1039/c1cp22831e

[25] P.A. Williams, C.E. Hughes, A.B.M. Buanz, S. Gaisford, K.D.M. Harris, Expanding the solid-state landscape of L-phenylalanine: discovery of polymorphism and new hydrate phases, with rationalization of hydration/dehydration processes, J Phys Chem C, 117 (2013) 12136-12145. http://dx.doi.org/10.1021/jp401547f

[26] J.P. Perdew, K. Burke, M. Ernzerhof, Generalized gradient approximation made simple, Phys Rev Lett, 77 (1996) 3865-3868. http://dx.doi.org/10.1103/PhysRevLett.77.3865

[27] M. Fleck, A.M. Petrosyan, Salts of amino acids, Crystallization, Structure and Properties. Cham, Switzerland: Springer International Publishing, (2014).

[28] A.B. True, K. Schroeck, T.A. French, C.A. Schmuttenmaer, Terahertz spectroscopy of histidine enantiomers and polymorphs, J Infrared Millim Te, $32 \quad$ (2011) 691-698. http://dx.doi.org/10.1007/s10762-010-9645-9

[29] Y.C. Shen, P.C. Upadhya, E.H. Linfield, A.Ga. Davies, Temperature-dependent low-frequency vibrational spectra of purine and adenine, Appl Phys Lett, (2003) 2350-2352. http://dx.doi.org/10.1063/1.1565680

[30] G. Smith, A. Hussain, N.I. Bukhari, I. Ermolina, Quantification of residual crystallinity in ball milled commercially sourced lactose monohydrate by thermo-analytical techniques and terahertz 
spectroscopy, Eur J Pharm Biopharm, $92 \quad$ (2015) 180-191. http://dx.doi.org/10.1016/j.ejpb.2015.02.026

[31] J. Lu, Characterization and pseudopolymorphism of 1-phenylalanine anhydrous and monohydrate forms, Afr J of Pharmaco, 6 (2012) 269-277. http://dx.doi.org/10.5897/ajpp11.842

[32] K. Siegrist, C.R. Bucher, I. Mandelbaum, A.R.H. Walker, R. Balu, S.K. Gregurick, D.F. Plusquellic, High-resolution terahertz spectroscopy of crystalline trialanine: Extreme sensitivity to beta-sheet structure and cocrystallized water, J Am Chem Soc, 128 (2006) 5764-5775. http://dx.doi.org/10.1021/ja058176u

[33] K.C. Oppenheim, T.M. Korter, J.S. Melinger, D. Grischkowsky, Solid-state density functional theory investigation of the terahertz spectra of the structural isomers 1,2-dicyanobenzene and 1,3-dicyanobenzene, J Phys Chem A, $114 \quad$ (2010) 12513-12521. http://dx.doi.org/10.1021/jp107597q

[34] M.D. King, T.M. Korter, Noncovalent interactions between modified cytosine and guanine DNA base pair mimics investigated by terahertz spectroscopy and solid-state density functional theory, $\mathrm{J}$ Phys Chem A, 115 (2011) 14391-14396. http://dx.doi.org/10.1021/jp208883t

[35] T.R. Juliano, T.M. Korter, Terahertz vibrations of crystalline acyclic and cyclic diglycine: benchmarks for london force correction models, J Phys Chem A, 117 (2013) 10504-10512. http://dx.doi.org/10.1021/jp407112w 


\section{Graphical Abstract}
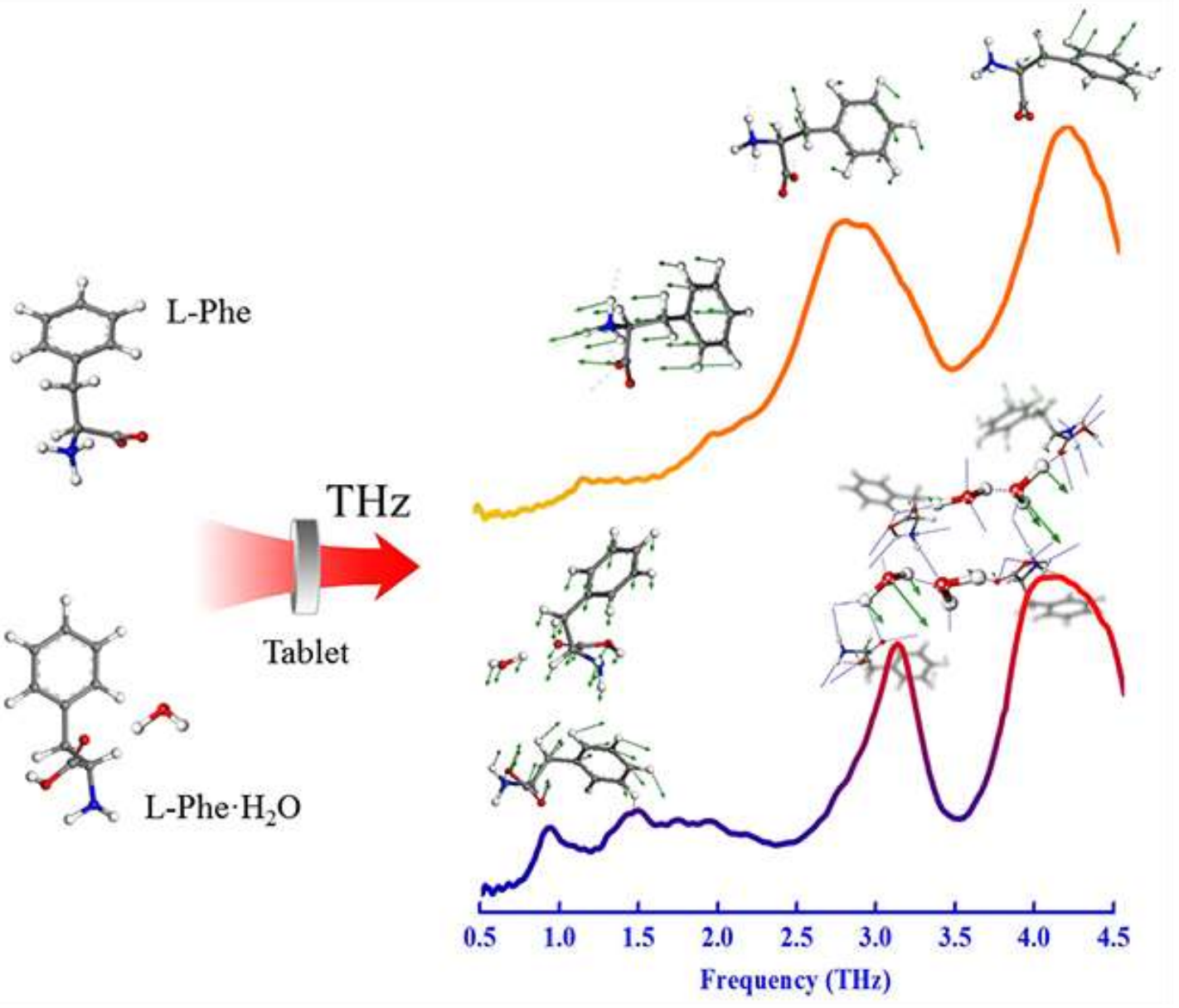